\title{
Ana Galvañ
}
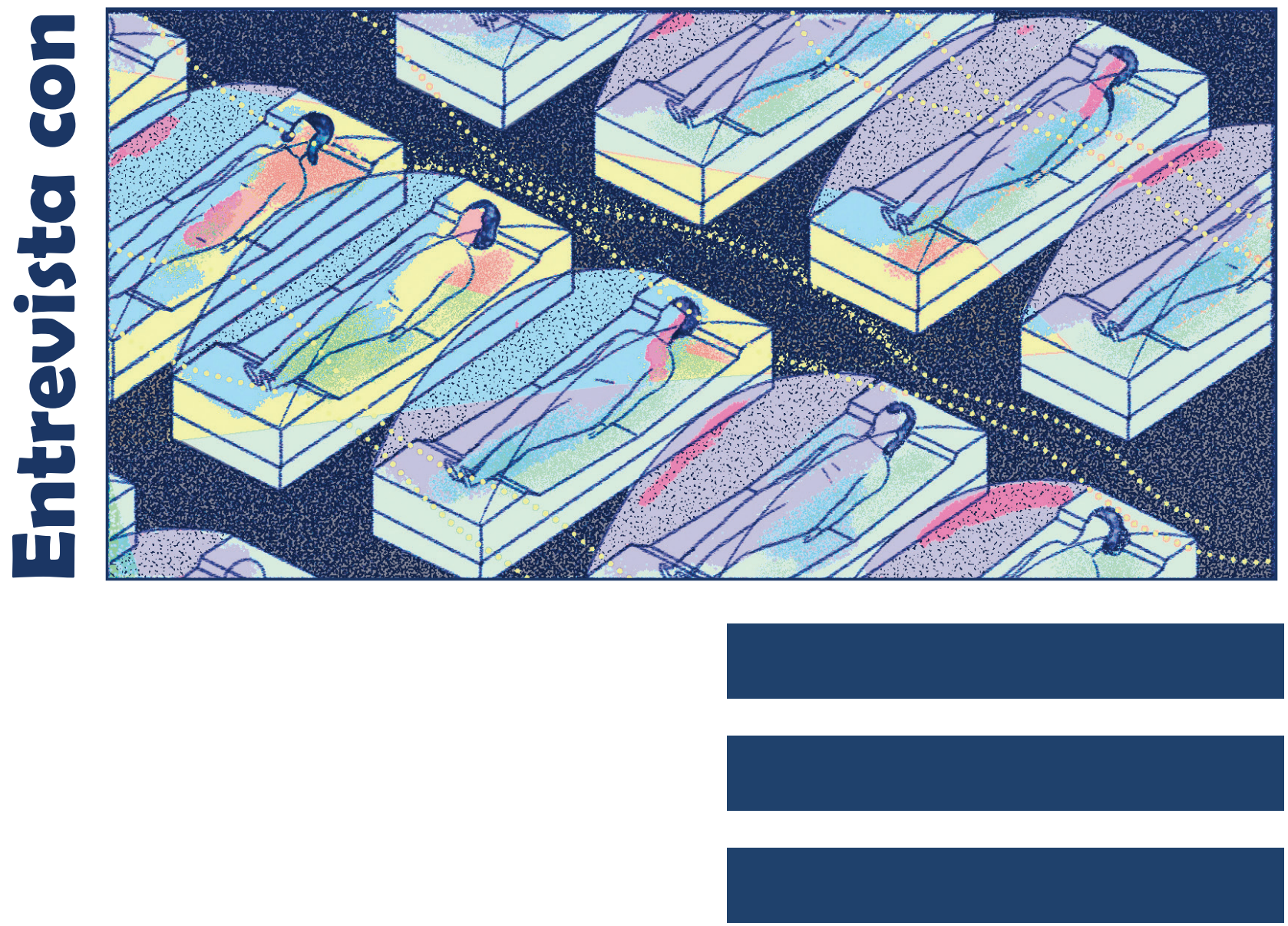

Imagen: Pulse Enter para continuar (Apa Apa, 2018) 


\section{CuCoEntrevista}

Ana Galvañ (Murcia, 1975) es una ilustradora y autora de cómic afincada en Madrid. Es además comisaria de exposiciones, impulsora del portal de cómic digital Tik Tok y muchas otras cosas. Es, en suma, una de las principales renovadoras del cómic español de los últimos años y una militante del fanzine y la autoedición. Hace unos meses, los codirectores de CuCo, Cuadernos de cómic, entrevistaron a la autora a través de una videoconferencia, conversación que fue ampliada cuando Galvañ publicó su libro Pulse Enter para continuar (Apa Apa, 2018).

Tú eres una autora de cómics tardía; no eres una dibujante que empezase joven, sino que comenzaste a publicar ya como una persona plenamente formada.

Soy la abuela rockera de los cómics [risas].

\section{¿Cómo entraste en este mundo?}

Bueno, yo sí era una lectora fanática de cómics, desde pequeña. Después estudié en la escuela de Arte, aunque tampoco dibujaba mucho en esa época. Pero siempre me acompañaban los cómics a todas partes. Si nunca se me había ocurrido dibujarlos era porque me parecía algo muy fuera de mis posibilidades, muy lejos de lo que yo podía llegar a hacer. Lo que sucedió es que me especialicé en diseño, y cuando ya estaba trabajando para agencias, empecé a dibujar con el programa de animación Flash. En esos momentos yo hacía animaciones para agencias de publicidad on line, y empecé a hacer unos personajitos con bocadillos... A la gente le gustaban, y a partir de ahí me animé más. Hice un par de historias que publiqué en un blog. David Rubín me invitó a participar en Barsowia, Puño me invitó a colaborar en an- tologías de la editorial Ultrarradio. Todo eso me hizo darme cuenta de que tenía algo que decir y que no estaba mal, y me animé.

\section{¿En qué época sucedió todo esto?}

Alrededor de 2008. Yo terminé Bellas Artes a principios de los 2000. Cuando empecé a hacer esos dibujitos que os decía, tenía 31 años ya.

\section{¿Y qué tipo de cómics leías antes de plan- tearte ser autora?}

En la escuela de Arte, como no tenía ni idea ni estaba formada, leía todo lo que me caía en las manos. Podía leer a Moebius, Elektra, manga - Akira, por ejemplo-, Enki Bilal. En ese momento yo era una esponja. Estaba descubriendo el cómic adulto y todo me parecía interesante, de alguna manera. En el momento en el que llegué a Daniel Clowes he de reconocer que me quedé bastante pillada. Hubo varios años en los que no salía de allí. Y en la época en la que empecé a dibujar, mis influencias eran más bien del cómic español. Las autoras y autores del fanzine Enfermo: Lola Lorente, Alber- 

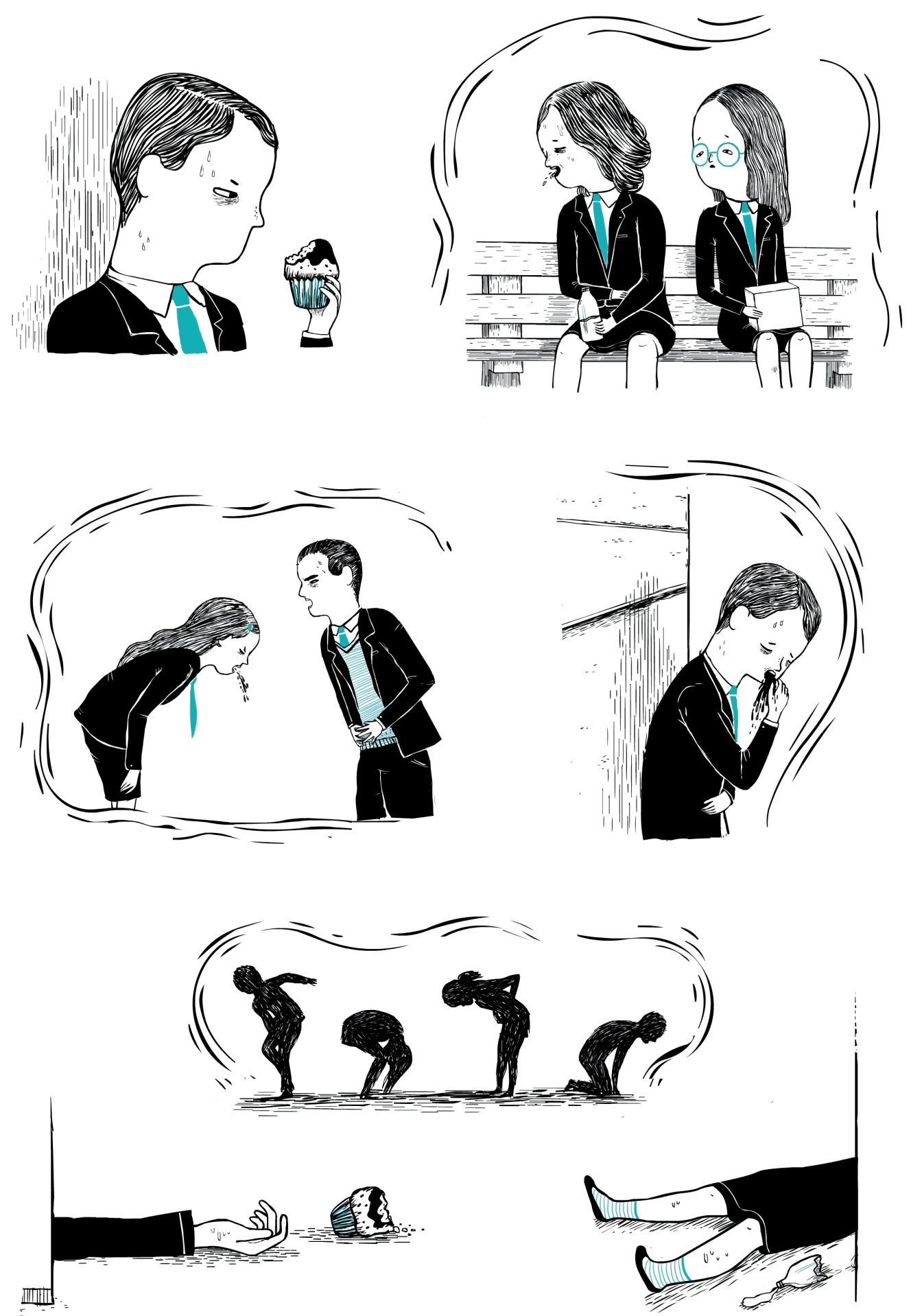

Página de una de las historias incluidas en Podría ser peor (Ultrarradio, 2012). 
to Vázquez... Esta generación me influyó y me hizo pensar que yo podía dibujar, porque este tipo de cómic me parecía más accesible, debido también al tipo de dibujo que hacían, menos ortodoxo. También me gustaban mucho Carlos Vermut, David Rubín... Me compraba en aquella época revistas como BDBanda, El Manglar, Nosotros Somos Los Muertos... Otra de las autoras que me animó a empezar a dibujar, que me encanta y que ha sido una influencia de primera magnitud fue Lilli Carré, que en aquella época había publicado en España La laguna (La Cúpula, 2009) o Cuentos de Pete el leñador (Apa Apa, 2010). En general, leía todo el cómic independiente que salía. Mucho americano, también: con Chris Ware estaba como loca.

Creemos que todas estas referencias que comentas se notan mucho en el primer libro que publicas, una recopilación de historias, Podría ser peor (Ultrarradio, 2012), que reunía las piezas que habías publicado previamente en antologías y revistas.

Sí. Estaba buscándome, entonces. Cuando las reuní en 2012, me di cuenta de que mucha gente las veía crípticas y raras, aunque yo no las veía así. No pensaba estar haciendo algo un poco más difícil, para mí, incluso hoy, siguen siendo sencillas. Pero sí, estaba buscándome, y por eso hoy no estoy super orgullosa de esa recopilación, porque la veo muy poco asentada, incluso temáticamente. Le falta coherencia. Pero, para entender el momento en el que estoy ahora, creo que puede resultar interesante.

Al final, todos los autores tienen que tener esa fase de búsqueda, salvo algún genio loco que pueda aparecer... Lo lógico es tener esa escalera.

Claro. Yo tengo historias más cercanas a Lola Lorente, más victorianas, otras en las que me parezco más a Carlos Vermut, claramente. Cada una es de su padre y de su madre.

También son historias que se realizan en un periodo de tiempo más o menos largo: en estos casos, es difícil que exista una coherencia, porque no se han hecho todas las historias en el mismo momento.

Sí: fueron historias realizadas 2008 y 2012.

Cuando lo leímos en su momento, nos resultó muy interesante, aunque es verdad que tiene poco que ver con lo que haces ahora, a nivel por lo menos estético.

Yo creo que sí fue interesante, y aún hay gente joven que me lo dice, que les influyó el hecho de ver al menos a alguien que estaba haciendo cosas raras. Se veía una inquietud de querer romper con algo, en esas historias. $Y$, además, tenía unos referentes cinematográficos, casi todos. Y me da un poco de rabia, porque yo había chupado mucho cómic. Hay muchas referencias del cine de ciencia ficción y terror.

Tú empiezas a publicar en un momento en el que se está empezando a reactivar la escena del cómic independiente; hasta ese momento costaba mucho publicar, no había tantas editoriales ni tantas opciones de micro y autoedición. Llegas a esa escena en el momento en el que está despegando, también con la celebración de cada vez más encuentros de autoedición. ¿Cómo has visto la evolución desde entonces al momento actual?

Yo empecé muy fuerte con Ultrarradio, que luego, desgraciadamente, se ha ido desinflando. Ahí había gente muy potente. Estaban Davín, Mireia Pérez, Puño, José Ja Ja 
Ja... Era un referente. A raíz de eso, empecé a moverme en los festivales de autoedición. Con Ultrarradio me fui a Tenderete, visité Fatbottom, luego fui al Gutter Fest, entré en contacto con la escena de Barcelona: Alexis Nolla, Marc Torices, Cristina Daura... Todo esto me influyó mucho. Esta generación tenía una nueva visión que aportó mucho. Por ejemplo, José Ja Ja Ja fue muy importante, y nos abrió la mente. Quizás sin todo eso yo no hubiera desarrollado mi trabajo de la manera en la que lo he hecho. Creo que he tomado un buen camino, pero, seguramente, yo sola no habría tomado ciertas decisiones.

Toda esta proliferación de pequeños festivales está generando un roce que va más allá del clásico encuentro anual en el Salón del cómic de Barcelona que es muy sano. También tiene que ver con internet, pero este fenómeno resulta nuevo en la historia del medio...

Sí; existe una retroalimentación tremenda, que enriquece la calidad del cómic en general. Hablo de la autoedición a todos los niveles: a mí lo que me más me interesa es el cómic, pero también me aporta mucho ver fanzines de diseño gráfico, de poesía, de cualquier otro ámbito. $Y$ todo eso hace progresar el medio. Y después están los pequeños contactos: yo fui al Gutter Fest y me tocó al lado de la mesa de Fosfatina, y conecté con su editor, lo que permitió pensar en proyectos comunes. Es la manera en la que empiezan a surgir este tipo de alianzas. Supongo que en el resto de países pasa lo mismo: en la microedición hay pocos enemigos. No es que exista una super hermandad, pero sí hay muchísimas alianzas entre las pequeñas editoriales y los fanzines. Se hacen cosas juntos... Roberta Vázquez, por ejemplo, hace un fanzine, y te llama para colaborar, luego tú haces otro y llamas a otra gente... Se crea un pequeño universo que creo que es necesario como motor para que esto funcione.

Nos sorprendió, en este sentido, encontrar en el primer número de un fanzine de Ourense, Finnegans, una historia tuya. También nos parece importante lo que has apuntado sobre que en estos festivales no solo se encuentra cómic, sino que también hay mucho de diseño, de música... Es muy positivo y también bastante rompedor con las formas de pensamiento tradicional del cómic que había en los ochenta, por ejemplo.

Sí, todo esto funciona muy bien en estos festivales. La falta de prejuicios y las ganas de abrir la mente a otras cosas están ahí. Yo no sé si en los ochenta era de otra forma, porque no lo viví, aunque creo que también hubo una escena rompedora, muy experimental y loca, con ganas de salir de lo ortodoxo. Pero no sé hasta qué punto se relacionó con otras áreas, supongo que sí.

Sí, si pensamos en Madriz, por ejemplo... Pero en los ochenta sí es cierto que la gente que hacía cosas más experimentales también se enfrentaba a las opiniones que no consideraban cómic lo que hacían, o que lo veían con recelo... Ahora creemos que existe más variedad; antes se circunscribía a cosas más concretas. Hoy en día formáis algo que creemos que puede denominarse comunidad. ¿Tenéis esa sensación de formar parte de algo conjunto, cuando os reunís?

Me hacéis una pregunta muy curiosa, porque creo que sí existe esa sensación de comunidad y existen grupos, por ejemplo, la gente en torno a Fatbottom en Barcelona, o en Valencia... En Madrid quizás hay me- 
nos, pero en Vigo hay un grupo muy claro... Depende de la ciudad. Pero yo me siento un poco en medio, quizás... No sé si porque soy de otra generación, pero a veces tengo la sensación de estar un poco sola. Me enriquece y me gusta todo esto, pero tengo la sensación de fondo de ir por mi cuenta. No he teorizado sobre esto; quizás a vosotros también os dé esa sensación sobre mí. No me siento parte al 100\% de esta movida, porque he vivido «otras vidas», y me quedan por vivir otras... Me siento un poco como un satélite que entra y sale de ese entorno.

Sí, entendemos lo que dices. Por cuestión generacional tienes otro bagaje, pero quizás la suerte que tienes es la de poder adaptarte a este presente con emoción.

Sí, creo que sí.

Repasando tus publicaciones, se aprecia que has publicado en la órbita de todos estos grupos: Fosfatina, Apa Apa... Pero no estás adscrita a ninguno de ellos, como dices, aunque estés en contacto con todos.

Sí, es que me interesa todo lo nuevo. Siempre me han interesado las innovaciones, el camino que está recorriendo el cómic hacia el futuro. Cada vez que surge alguna nueva iniciativa establezco relaciones con ella. Pero creo que no me quedo «enganchada» con ninguna... Supongo que en algún momento ya seré tan carroza que dejarán de hacerme caso las nuevas generaciones [risas]. Pero, por ahora, establezco contactos y me funciona esta manera de hacer. Por un lado, me divierte, y, por otro, aprendo de todos ellos. Sin querer compararme, por supuesto, creo que hago algo parecido a Max.

Después de aquel recopilatorio, ¿̨lo siguiente que haces es Trabajo de clase (Apa Apa, 2014)?

Sí, pero, paralelamente, siempre he seguido haciendo historias cortas para fanzines y cosas por el estilo. Y, como ya no las quiero recopilar, la verdad es que no tengo muy claro el orden cronológico de lo que voy haciendo. Pero sí: después de Podría ser peor lo más largo que hice fue lo de Apa Apa.

Fue un cómic reversible con Marc Torices, que hacía otra historia, Nuevos románticos, pero también había unas páginas centrales donde dibujabais entre los dos.

Sí, el caso es que desde Apa Apa nos lo propusieron. Ya sabéis que en aquella época estaba cambiando su dinámica para centrar-

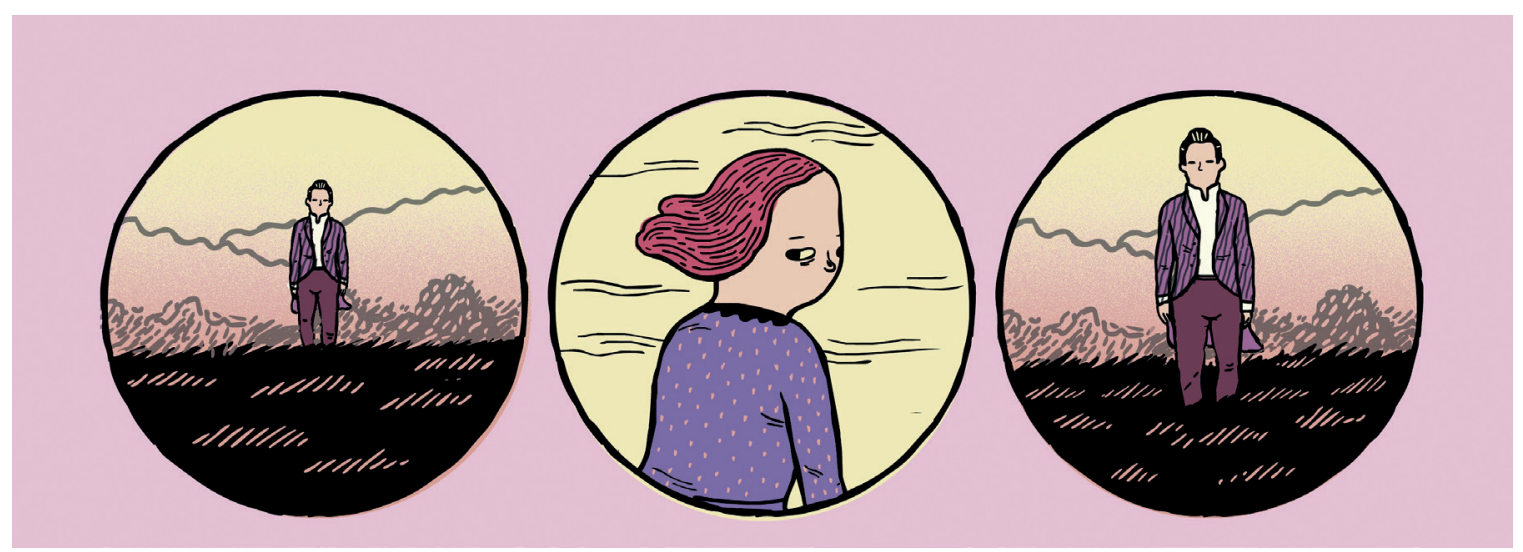

Detalle de una página de Trabajo de clase (Apa Apa, 2014). 
se en autores y autoras nacionales, y sacar algunas cosas en grapa. Se les ocurrió esta colección, Grapa Grapa, con este formato reversible con historias de dos autores. A mí me propusieron hacerlo con Marc, y como admiro mucho su trabajo me hizo muchísima ilusión. Además, Apa Apa siempre ha sido para mí una de las editoriales de referencia, por no decir la editorial de referencia nacional. En principio iba a ser algo mucho más corto, pero como Marc es una bestia parda que se puso a hacer veinticuatro páginas a todo color, yo le tuve que seguir el ritmo, y al final hice otras veinticuatro. He de decir que la historia de Marc me parece muy superior a la mía, pero aprendí muchísimo de él.

Viéndolo con perspectiva, ¿se puede ver este trabajo como un punto intermedio entre tu obra primeriza y lo que estás haciendo ahora? Estéticamente había rasgos de ese primer estilo, pero ya estabas apuntando ciertos cambios en composición de página y secuenciación.

Sí, es un punto intermedio dentro de una progresión. Dentro de unos años seguramente se verá más claro, pero creo que hay una progresión estilística, y también temática, porque quizá a mí en esa época me interesaba más la ingenuidad, y ahora la estoy abandonando un poco. Nunca la soltaré del todo, ni ese tipo de humor un poco tontorón, pero en ese momento estaba más enamorada de ese universo adolescente, de sus pulsiones primarias.

También hiciste alguna historia, como en Verde (Autsaider, 2013), donde se empieza a ver ese cambio en la composición, más allá de que el estilo de dibujo sea más o menos geométrico. Hay una evolución en la manera de plantear la página.
Sí, empieza a ser menos indie. Hasta entonces mi influencia más poderosa había sido el indie americano, la línea clara, los colores planos... En ese momento me voy a las dos tintas, o a una sola tinta, empiezo a experimentar con texturas, por ejemplo, a través de la risografía, y también con la composición de página. Empiezo a romper por ahí, a quitarme el miedo a que me salieran cosas pedantes, me daba mucha vergüenza, y en ese cómic [Trabajo de clase] quería mezclar lo adolescente con algo un poquito más sesudo. Pero siempre con mucho humor, porque le tengo respeto a hacer algo pretencioso, me da mucho reparo.

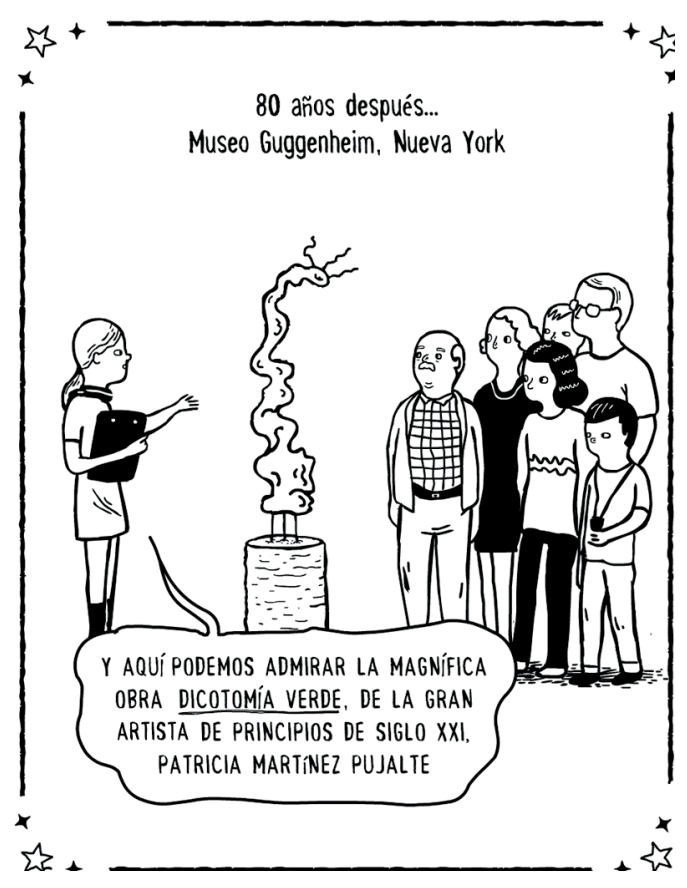

Página del minicómic con el que Galvañ participó en la caja Verde (Autsaider, 2103).

Otro trabajo interesante, ahora que mencionas la risografía, es Luz verdadera (Fosfatina, 2016), un proyecto de edición limitada.

Por motivos personales, estuve dos años muy parada, y me costó volver a publicar. El trabajo de ilustración me ocupaba todo el 

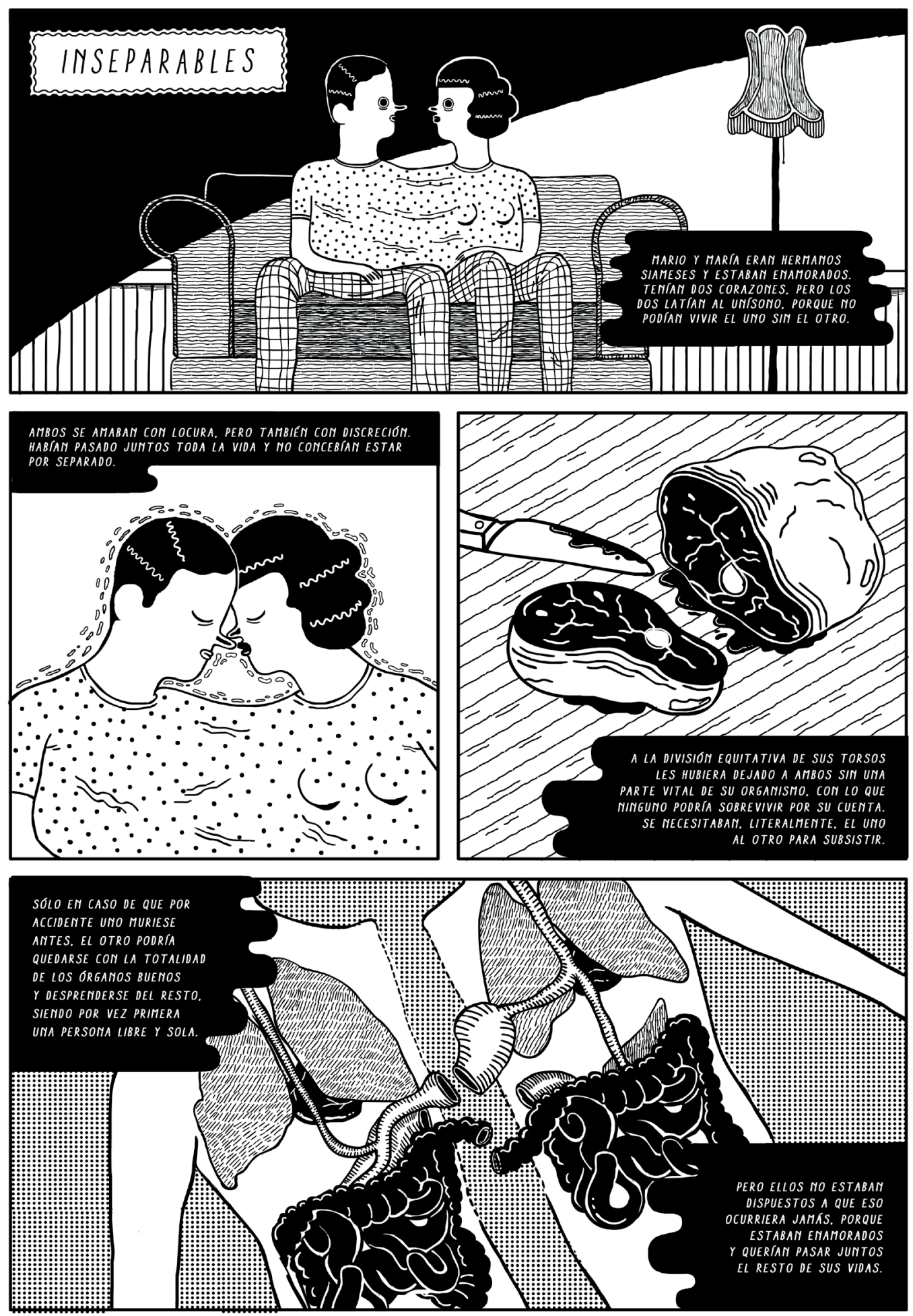

Página de «Inseparables», la historia de Galvañ incluida en Todas putas: los cuentos gráficos (Dibbuks, 2014). 
tiempo, pero ahora vuelvo a estar muy animada. También tuve una crisis a nivel creativo. Empezaron a dejar de gustarme mis propias historias y por dónde iban.

Así que cuando desde Fosfatina me llamaron para participar en la colección Fosfatina2000 me animé mucho, tenía ganas de hacer cosas nuevas y el formato era ideal. El trabajo en dos tintas me obligó a trabajar de forma diferente. Además, creo que en Luz verdadera se ven las últimas influencias en mi trabajo de Michael DeForge, que es un autor que creo que ha hecho algo importante en el universo de lo independiente. Cuando empezó a experimentar estaba más solo y siempre siguió su propio camino. Creo que su obra Ant Colony (Drawn \& Quarterly, 2014) marca un antes y un después.

En este cambio en el enfoque de tu trabajo, ¿tiene algo que ver tu faceta como ilustradora? ¿Hay muchas diferencias entre un medio y otro?

Pues sí: cada trabajo que hago influye en mi trabajo posterior. Por ejemplo, la risografía me abrió un mundo. Empecé a dejar de usar el color como algo simplemente decorativo. Cada vez que alguien me propone un trabajo que se sale de mi zona de confort me hace crecer... Odio esa frase, pero ya la he dicho [risas]. Por ejemplo, la serigrafía para $\mathrm{CuCo}$, que me pedisteis a dos tintas - y que fue mi primera serigrafía-, me obligó un poco a experimentar y multiplicar capas para conseguir otras tonalidades. $\mathrm{Y}$ ahora es un recurso que estoy utilizando, tanto en cómic como en ilustración. O sea que sí, lo que hago en el cómic me influye en la ilustración, y viceversa.

Una de nuestras historias favoritas es tu contribución a Hoodoo Voodoo (Fosfatina,

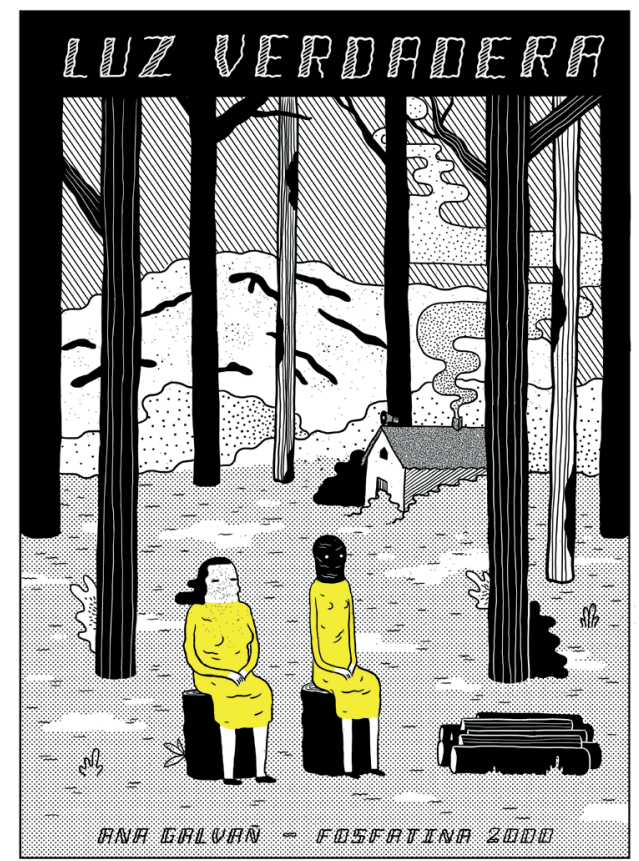

Cubierta de Luz verdadera (Fosfatina, 2016).

2016). En historias tan extrañas y oníricas, cabe preguntarte de dónde sale todo eso: si partes de una imagen, $o$ de una idea...

No lo sé. Yo tengo siempre apuntadas ideas, y tenía una para representar distintas acciones de un personaje en un mismo espacio. Eso lo tenía claro. Lo que pasa es que tardé en plasmarla, era difícil formalizar esa idea. La aparición del televisor es una constante: me obsesiona, sin saber por qué. Y el tigre aparece porque necesitaba un elemento peligroso para que el personaje reaccionara y huyera. También quería experimentar un poco con las perspectivas: hay cuatro o cinco diferentes. No son exactamente caballeras o isométricas: yo pongo dos líneas en perspectiva a lo loco y a partir de ahí hago los dibujos. La forma de las viñetas, en este caso, se deben a que también quería trabajar con cierta idea de pliegue espaciotemporal, de viñeta tipo acordeón, que se desplegara 
y volviera a plegar, que hiciera zoom. Estoy aún bastante orgullosa de esa historia, ya la odiaré más adelante [risas].

También has colaborado en los números 2 y 3 de Voltio (La Cúpula, 2016). ¿Encaras de forma diferente la colaboración con una editorial más grande como puede ser La Cúpula, en contraposición a la microedición o la autoedición?

No, no hay diferencia. Yo hubiera enviado lo mismo a un fanzine. Porque era un proyecto muy personal de Ana Oncina y Álex Giménez. La idea original era hacer una cosa más fanzinera, y esa sensación permaneció. Yo siempre me lo tomé así, aunque estuviera $\mathrm{La}$ Cúpula detrás. Yo tampoco sabía la magnitud que iba a tener Voltio, porque pensaba que iba a tener una tirada más pequeña, con

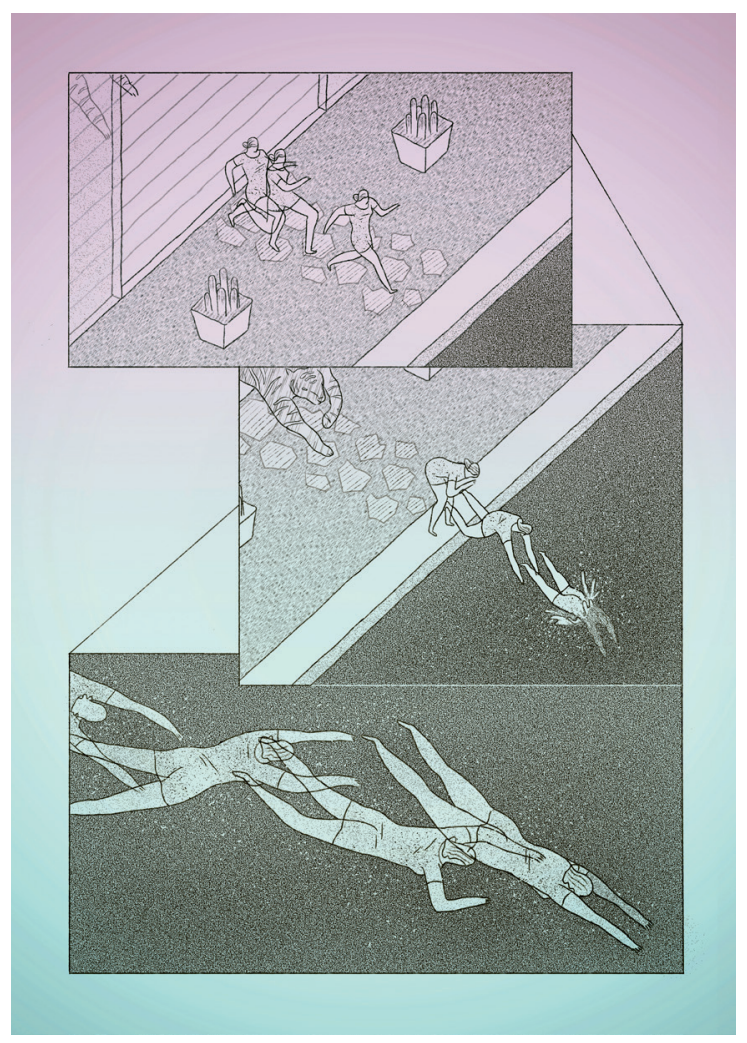

menos repercusión. Pero sí, ha funcionado muy bien. La portada del primer número me la pidió Ana Oncina, una amiga con la que tenía ganas de colaborar. Y en el segundo y en el tercer número envié historias que ya tenía hechas, no fueron ex profeso para Voltio, pero no habían sido publicadas en España.

Ese es otro tema interesante: la colaboración en publicaciones extranjeras. Has colaborado en la editorial Kuš!', hace poco, y esto quizá tiene que ver con lo que comentábamos del sentido de comunidad, solo que en este caso también sería internacional.

Sí, además la editorial Kuš! es una referencia. Me apetecía mucho colaborar y cuando David [Schilter] me llamó no lo pensé. Tam-

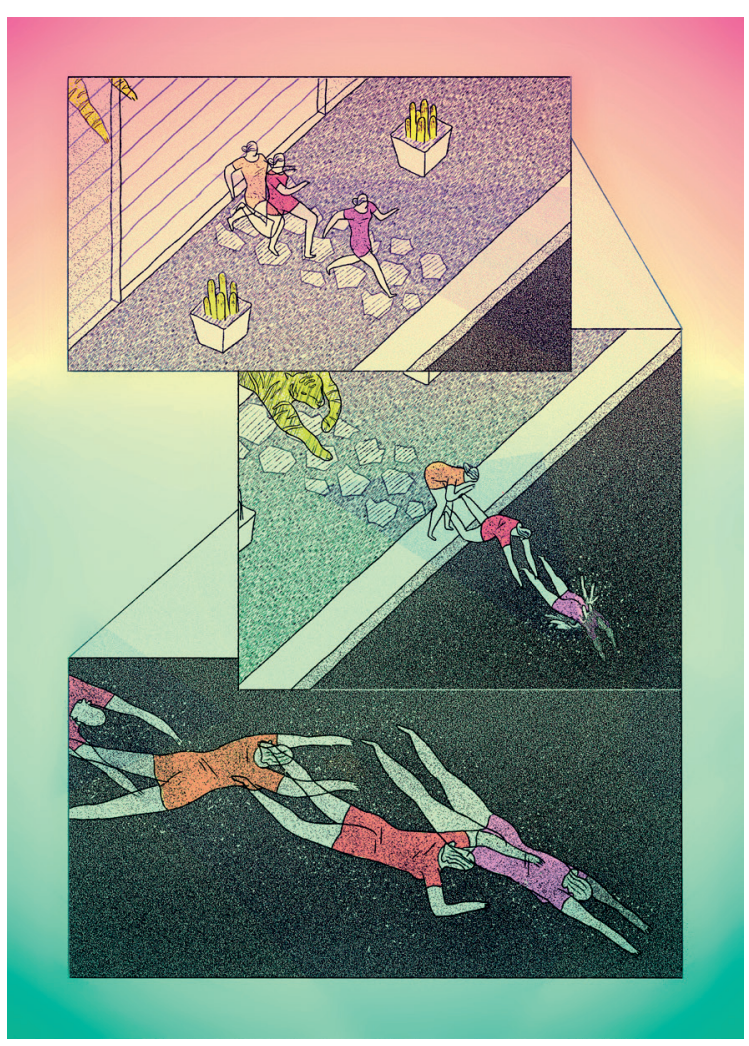

Izda.: página de la historia original incluida en Hoodoo Voodoo (Fosfatina, 2016); Dcha.: la misma página coloreada para su publicación en Pulse Enter para continuar (Apa Apa, 2018). 
bién me pasó con Hoodoo Voodoo. En una antología, cuando me gustan tanto los editores como los participantes, de alguna manera inconsciente intento hacerlo mejor, estar a la altura. $Y$ eso hace que mi trabajo crezca.

Comentabas que no había diferencias en cuanto a cómo afrontas el trabajo en función de para qué editorial sea. Nos imaginamos que en la ilustración será diferente, según el cliente, ¿no?

Sí. Hace un año, mi tendencia era a minimizar el color, hacer cosas con colores apagados, tipo rosáceo o gris. Estaba en una etapa «anticolor». Pero a raíz de que los clientes me exigen mucho color, porque es mucho más comercial y estamos en una época en la que eso se lleva, he vuelto a ello. Ha modificado mi forma de trabajar. Por otro lado, temáticamente, no me están limitando. Estoy haciendo trabajos editoriales, y en este campo se trabaja con poco margen de tiempo. En general, me dan un texto y me permiten que lo interprete libremente.

También has hecho campañas institucionales, para el ayuntamiento de Madrid, por ejemplo, o una campaña publicitaria para Kutxa Bank. En estos casos, ¿̇también te dan libertad o te marcan alguna pauta de lo que quieren?

Pues en Kutxa Bank la directora de arte era Elizabeth Casillas, así que consiguió que el cliente me diera mucha libertad. Sí me dieron unos temas a tratar. Era curioso, porque fueron muy abiertos a que hubiera diversidad de familias, por ejemplo, con dos mujeres, o con enfoque feminista. Gráficamente, como es habitual, me pidieron mucho color, pero, por lo demás, no me pusieron ninguna objeción a lo que yo les presentaba. Fue un trabajo de encargo que ni siquiera firmé, pero resultó que, como me dejaron tanta libertad, se me reconocía totalmente, mi estilo afloraba de una forma que no podía ocultar la autoría.

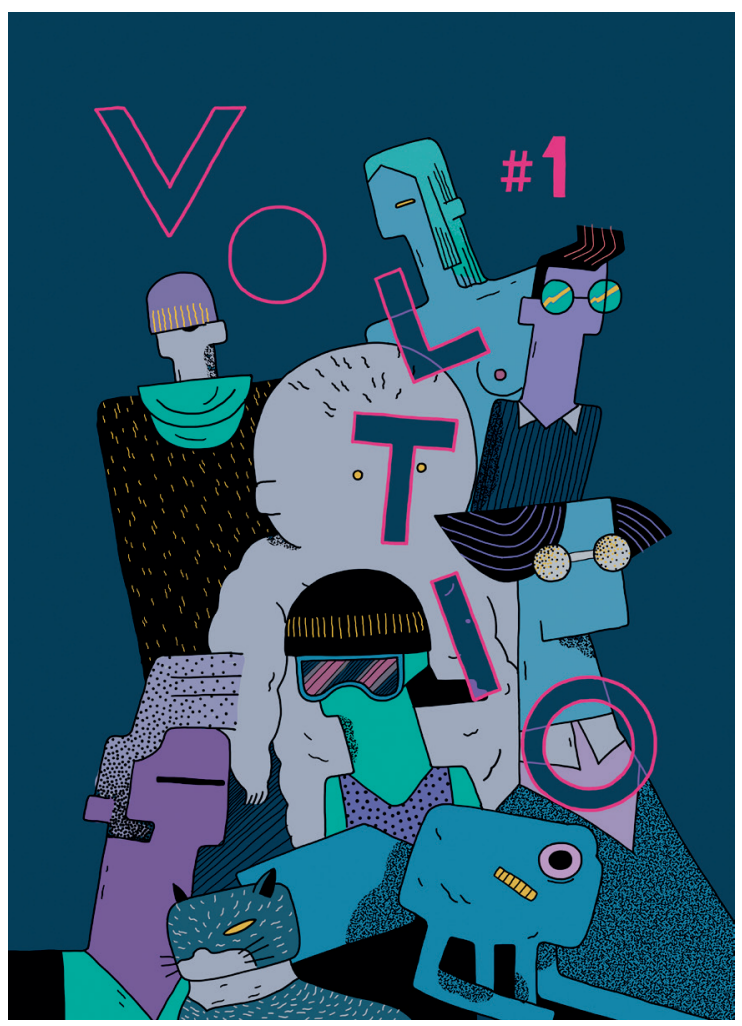

Cubierta de Voltio n. ${ }^{\circ} 1$ (La Cúpula, 2016).

Tú has formado parte de una expedición de autores españoles que, gracias a Spain Arts \& Culture, visitó la SPX de Baltimore en 2016. También has estado recientemente en la feria del libro de Guadalajara, México, con otros dibujantes. ¿Cómo valoras estas iniciativas?

Muy positivamente, como no podía ser de otra manera. El trabajo que está haciendo Acción Cultural Española para llevar el cómic español a otros países es muy importante. Tened en cuenta que yo también fui invitada al festival Entreviñetas en Colombia y ellos también colaboraron en el viaje. A veces me pregunto por qué voy yo a este tipo de viajes. Pero me dicen que, aparte de ser 
autora, tengo algo que ver con la divulgación del cómic más minoritario y fanzinero, hay personas a las que les parece importante que esté yo para dar a conocer en estos sitios el trabajo más minoritario. $Y$ también el de muchas autoras. Cuando estuve en la SPX me preguntaban si es que en España no había autoras de cómic, o si eran pocas. En Spanish Fever (Fantagraphics, 2016) no hay tampoco mucha representación de autoras, quizás porque es un proyecto anterior al boom de autoras en la autoedición. ${ }^{1}$ Así que creo que fue importante dar esa visión. Sobre todo, en EE. UU. En Latinoamérica creo que nos conocen más, tienen más interés. Pero en EE. UU. somos muy desconocidos para ellos.

\section{¿Percibiste interés por parte del público estadounidense? Porque hicisteis varios actos, algunas charlas, masterclasses...}

Sí, percibí interés por parte de periodistas, emisoras de radio... El propio festival nos puso en su programación junto a gente de la talla de [Daniel] Clowes o [Charles] Burns. $\mathrm{El}$ interés era claro. Por parte del público, me di cuenta, mientras dábamos una charla, de que, aunque nos esforzábamos por hablar en inglés, casi todo nuestro público era hispanohablante. Inmigrantes españoles, hispanos, o segunda generación de inmigrantes. Creo que a los americanos les cuesta un poco más, están muy centrados en lo suyo. Aunque, por otro lado, he de decir que en la autoedición sí que hay más lazos, a través de las redes sociales se conocen a algunos autores: por ejemplo, Gabriel Corbera. David Rubín, de los que íbamos en la expedición,

1 Spanish Fever fue la versión estadounidense de la obra colectiva Panorama: la novela gráfica española boy (Astiberri, 2012), un libro coordinado por Santiago García. Ana Galvañ participó en la edición estadounidense con su historia Más allá del arco iris. era el más reconocido en la feria. Otro de los autores que más se conocen allí es Max.

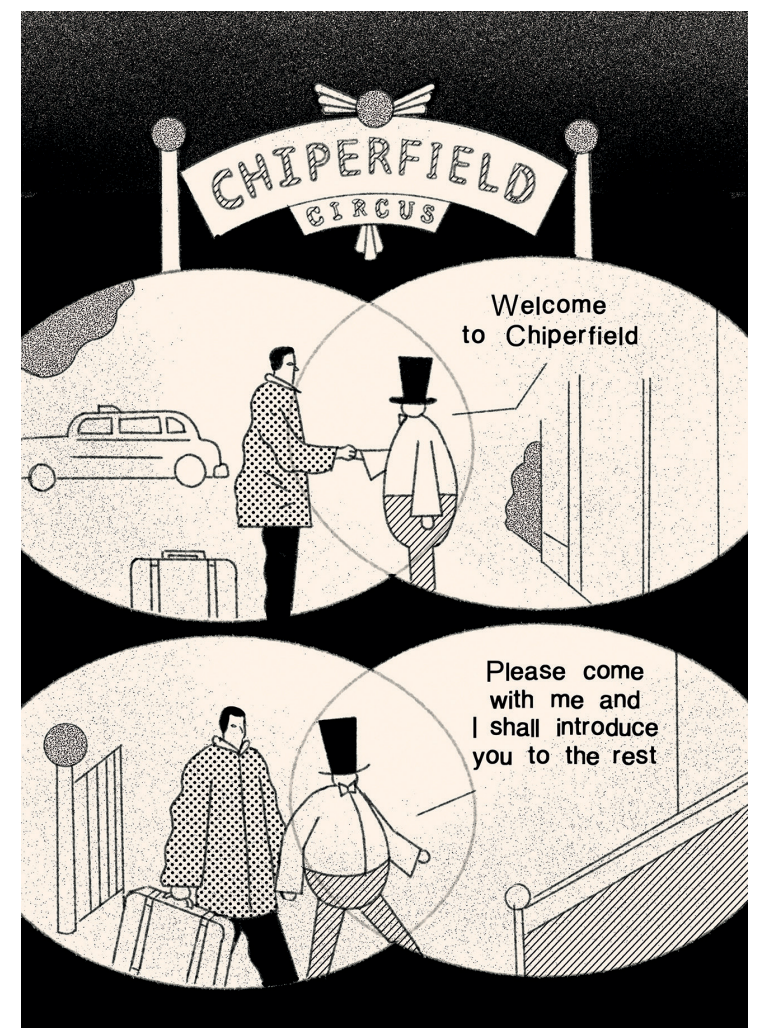

Página de la historia corta publicada en $\check{S} !$ n.o 28 (Kuš!, 2017)

\section{Ahora parece que están empezando a pu- blicar obras de aquí, ¿verdad?}

Sí: Fantagraphics tiene mucho interés. Siempre ha tenido interés en el cómic europeo, y ahora, a raíz de publicar a Joan Cornellá, Spanish Fever y la versión en inglés de Arrugas de Paco Roca - a Max lo venía publicando desde hacía tiempo-, se empiezan a interesar en las nuevas generaciones, como es el caso de Ed Carosia - argentino, pero afincado en Barcelona- o Conxita Herrero, quien va a participar en una nueva revista orientada a autores emergentes.

Y el mainstream está tirando de autores de aquí como David Aja o Javier Pulido... 
Pero ¿es posible que sigan siendo un poco ombliguistas a la hora de reconocer el cómic español? Que estos autores que trabajan en Marvel o DC sean visto como mano de obra, sin interés por sus mercados de origen.

Bueno, mainstream y no tan mainstream, porque Emma Ríos, por ejemplo, se mueve entre los dos mundos. Los autores españoles aportan frescura. Por ejemplo, en Aja se nota mucho la influencia de Ware, del cómic más independiente. Marcos Martín tiene muchas cosas de diseño gráfico, y la propia Emma proviene del mundo fanzinero gallego. Y yo creo que esa originalidad es importante. Han tardado en darse cuenta, pero han visto un nicho ahí. Quizá en el sector más independiente, de editoriales tipo Fantagraphics, hay una tradición tan fuerte de cómic más underground que quizá a los españoles les cuesta más abrirse en ese sentido. Pero creo que en cuanto un par de autores funcionen irán publicando más cosas.

Has comentado cosas interesantes respecto a la diferencia entre el mainstream comercial y toda esta nueva escena. ¿Tú percibes distancia entre ambos mundos? Parece que hay aficionados al cómic más tradicional a los que no les interesa el trabajo que hacéis vosotros.

Yo creo que el cómic emergente, por no usar la expresión de nueva ola, que no me gusta mucho, está más enfocado a nuevos lectores con una visión distinta del cómic y menos prejuicios. No creo que podamos reenganchar a lectores más tradicionales. Incluso a los que vienen de la época de El Víbora y todas estas revistas, de alguna manera, se han quedado muy enganchados a los ochenta y noventa. Yo tengo amigos, incluso más jóvenes, que están enganchados a esa época, a
Moebius... Ese tipo de público está perdidísimo, es muy difícil. Pueden conectar con un par de cositas de ahora, pero con todo lo que está pasando... ni de lejos. No tiene sentido hacer ese esfuerzo. No merece la pena cuando tienes muchísimo público en festivales como GRAF, Gutter Fest, Tenderete o No Tengo Mamá que se interesa mucho por todo esto. Las cifras de asistencia de GRAF, por ejemplo, han sido altísimas. ${ }^{2}$ Por eso soy optimista en este sentido.

Hay también un interés por parte de los medios de comunicación. Tú has colaborado con El País, por ejemplo. Ha habido colaboraciones en La Voz de Galicia de autores en esta línea, o incluso un programa televisivo como Página Dos se permite el lujo de entrevistar a autores...

Sí: a Roberta Vázquez, a José Ja Ja Ja, a los editores de Fulgencio Pimentel.

Quizás, entonces, haya una vía ahí para ligar el mundo más masivo y este circuito minoritario. ¿Cómo ves el papel de los mass media con respecto al cómic?

Hace unos años veía la cosa muy floja. Veía cómo en El País salían jóvenes interioristas, o diseñadores, pero nada de cómic. Pero ahora está cambiando la cosa muchísimo, y creo que también se debe a la renovación de los directores de arte y de las personas que trabajan en esos medios. Están entrando nuevas generaciones más interesadas en lo que está sucediendo ahora. Creo que hay algunos medios que se quedan en las viejas olas, tipo la revista $M 21$, a la que le está costando un poco renovarse, pero en cambio

2 Galvañ se refiere a la edición en Madrid de GRAF de 2017, celebrada unas semanas antes de tener lugar esta entrevista. 


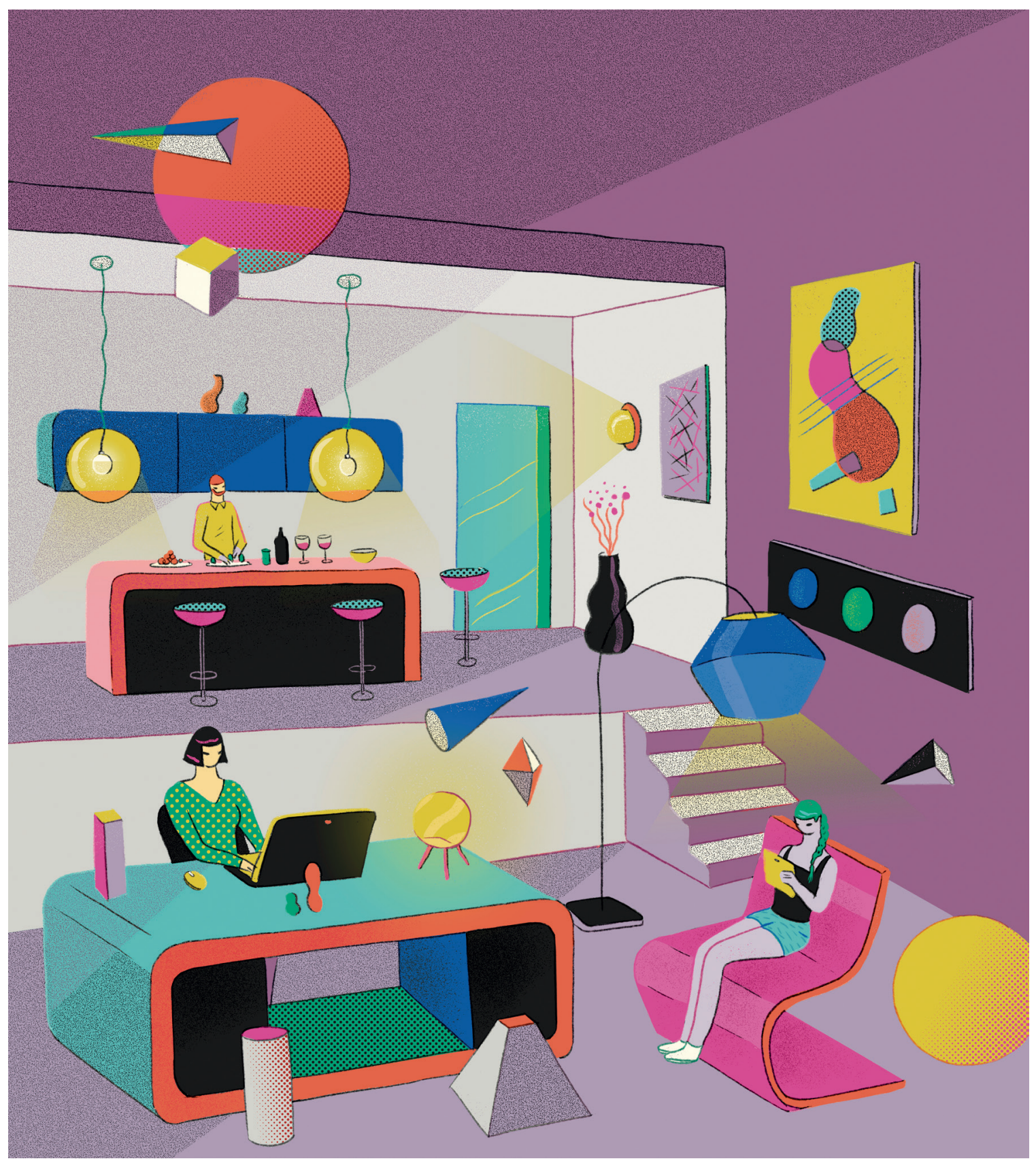

Una de las ilustraciones de Ana Galvañ para la campaña de Kutxa Bank.

otras están más abiertas. Creo que en El País hay varios directores de arte que vienen de medios como VICE y están abriendo paso a este tipo de trabajos experimentales. No es como la movida de los ochenta, que llegó a todo el mundo y salió en programas de televisión de máxima audiencia; desafortuna- damente se está quedando en círculos más pequeños. Pero, bueno, está llegando a un porcentaje de gente apreciable. Pero lo que sí observo es que siempre es una cuestión de personas concretas. En el ámbito institucional, igual. En Centro Centro estaba Tevi de la Torre, manejando los hilos para que este 
tipo de propuestas llegaran a los lugares de exposición. Fue la coordinadora de Animal Collective, - una exposición que comisarió la editorial Fulgencio Pimentel- que fue importantísima, y también fue la impulsora de La ciudad en viñetas, el ciclo que ahora coordino yo.

\section{¿Cómo es tu trabajo con La ciudad en vi- netas? ¿Tienes libertad total para escoger a las personas que participan?}

La verdad es que estoy muy contenta. Nunca había hecho esto antes, pero ahora parece que la labor de comisaria se ha convertido en otra faceta profesional para mí. Me dejan libertad total para elegir a la gente, nunca me han puesto ninguna objeción a nada de lo que he propuesto. Y, por mi parte, también les dejo libertad total a las autoras y autores para hacer lo que quieran, relacionado con Madrid. No intervengo. A no ser que haya algo que sea un fallo claramente, o una errata. Intento ayudar, eso sí. Hay quien pide más ayuda y quien prefiere hacerlo por su cuenta y entregarlo finalizado. Pero, hasta ahora, todos los trabajos han sido muy potentes. Me gusta sacar a la luz institucional a gente que proviene de mundos muy pequeñitos, con un talento enorme. Me encanta llevarlos del

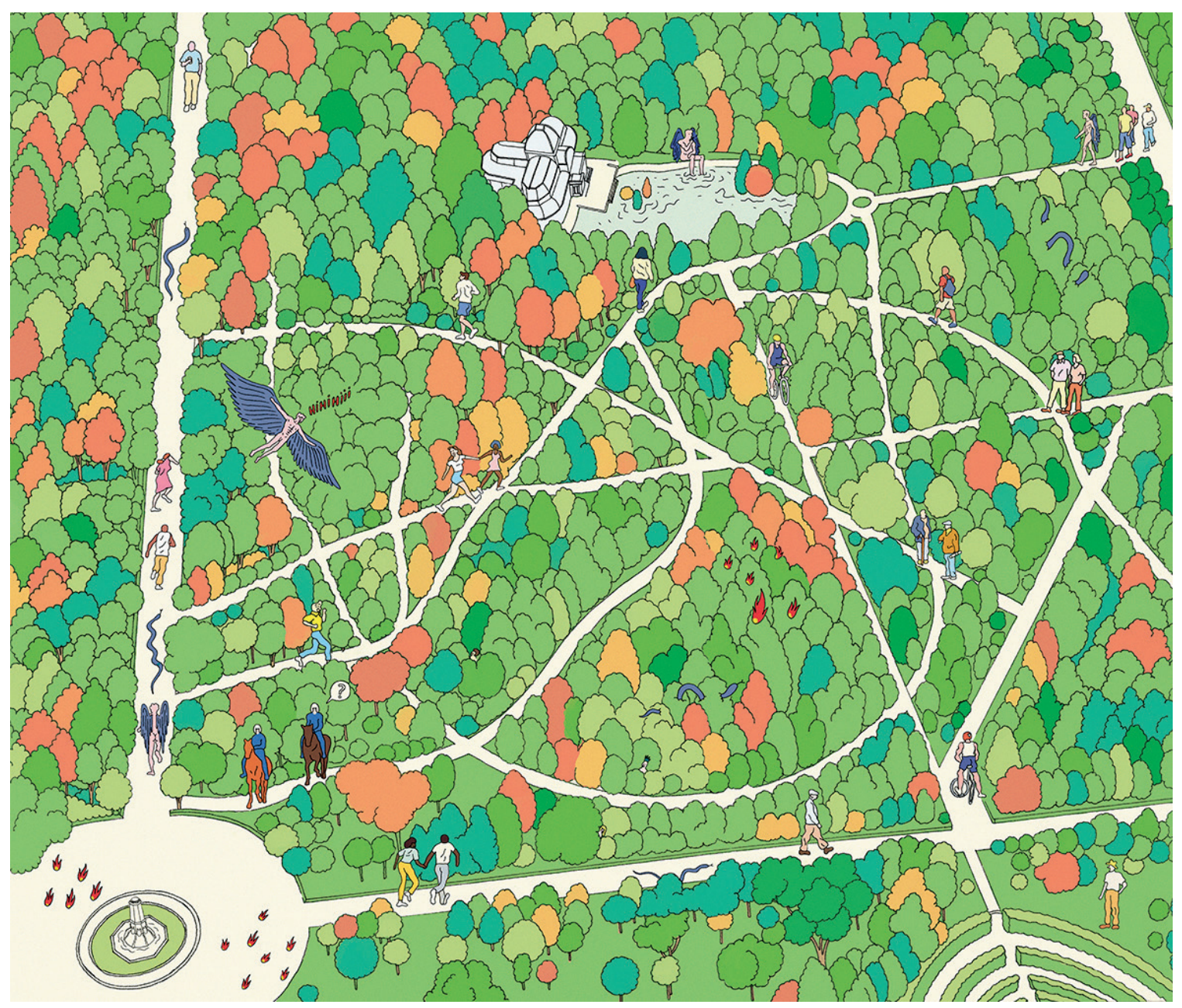

Un detalle de la última exposición del ciclo La ciudad en viñetas, obra de Pepa Prieto Puy. 
fanzine pequeñito a un gran formato como el que usamos aquí. Que puede haber cierto debate sobre si un mural puede ser cómic... Pero creo que debemos abrir la mente. El mural es interesante porque los autores saben que el público lo va a leer de forma distinta, de pie, y eso obliga a estructurar el cómic de una forma muy diferente.

Quizá todo este nuevo cómic está replanteando muchas cosas que tienen que ver con el lenguaje del medio, y de ahí la ruptura con cierto tipo de aficionados que entiende el cómic como algo intrínsecamente narrativo, para contar buenas historias «bien dibujadas». Vosotros estáis trabajando en paradigmas muy distintos, y en contacto con otros medios artísticos.

Sí, pero yo opino que, al final, hay un cambio de paradigma. Y se está viendo que es un medio. Yo lo comparo con la televisión, porque me parece una analogía bastante clara. Tú en televisión puedes ver un programa de sábado por la noche o una serie con una producción independiente, y no pasa nada. Tienes a mi madre viendo; Qué tiempo tan feliz! y a mi hermana viendo Twin Peaks y nadie tiene ningún problema. No sé por qué lo tenemos en el cómic. El cómic más experimental tiene un público, y el de aventuras tiene otro. Y no debería afectarnos. De hecho, me parece algo muy lógico.

Es un camino por el que se está avanzando, en los últimos diez años. Tu opinión está cada vez más extendida entre la gente que está un poco metida en el medio, está cuajando. Pasamos de la discusión sobre la novela gráfica a la consolidación de este paisaje plural.

Qué bonito, «paisaje plural» [risas]. A mí me gustaría aportar algo a ese debate sobre la novela gráfica. Últimamente me pregunta mucha gente joven, con mucha ingenuidad al respecto, que en qué se diferencia la novela gráfica del cómic. No lo entienden. Yo les digo que no se diferencia en nada [risas]. Creo que se está quedando un poco anacrónico el término. Quizás en un momento fue útil, pero ahora despista mucho. También hay personas que piensan que diferencia el buen cómic del cómic menor, o que los fanzines se quedan fuera... Que casi hace más mal que bien.

Nosotros creemos que el trabajo de gente como tú misma, Marc Torices o Cristina Daura ya no se ajusta a la idea más o menos convencional que tenemos en la cabeza cuando pensamos en la novela gráfica, que puede ser Maus o Persépolis... Lo que hacéis es otra cosa. Santiago García ha hablado de posnovela gráfica. ${ }^{3}$

Hay quien la defiende como un formato, también. Lo que pasa, entonces, es que cuando se hace una mesa redonda sobre novela gráfica, se quedan muchas cosas fuera. A mí me han dicho «lo que tú haces no es novela gráfica». Ok, no hay ningún problema, pero entonces yo no puedo estar en esta mesa redonda. De esa manera se excluye, sin quererlo - porque no hay mala intención, por supuesto-, y creo que es injusto e innecesario.

Lo que sí se comparte, en todo caso, es la libertad creativa. Dentro de la novela gráfica se enfatiza la iniciativa autoral, y creemos que eso sí lo compartís, hay una misma sensibilidad hacia el medio, de hacer

3 García, S. «Regreso al futuro», en Mandorla (26 de abril de 2013). Disponible on line en http:// santiagogarciablog.blogspot.com/2013/04/regreso-al-futuro.html 


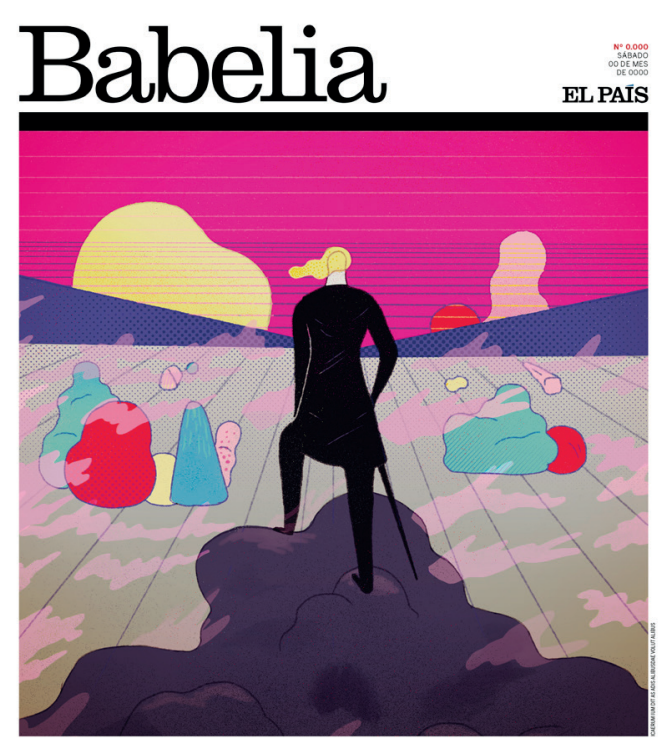

Portada para Babelia, el suplemeno cultural de El País.

cosas personales. David Rubín, por ejemplo, suele argumentarlo así. Pero es verdad lo que comentas, hay toda una nueva movida de fanzines $y$ pequeñas ediciones para la que se queda corta la reivindicación de la novela gráfica.

Creo que es el momento de dar un paso hacia delante en este sentido, sí.

Hay otra cuestión fundamental: el boom de autoras que se está dando. Cuando vamos a un GRAF, vemos un 50\% de autoras, incluso a veces hay más autoras que autores. ¿Por qué crees que ha pasado esto ahora?

No lo sé, no tengo una teoría. Pero me estoy dando cuenta de que están casi todas en la autoedición. Hay mucho talento, pero no sé si esta industria, que ha sido tradicionalmente masculina, les va a permitir profesionalizarse. Ya sabéis que la invisibilización de la mujer es algo muy velado, y algo, a veces, inintencionado. Hace cinco o seis años hubo una ola de fanzineras, como podían ser Luci Gutiérrez o Lola Lorente, y tampoco se han profesionalizado todas, al igual que sus compañeros. Alguien como Lilly Carré ha dejado de hacer cómics para dedicarse al arte. A mí me gustaría que continuaran con el trabajo que están haciendo muchas de estas mujeres, porque me parece increíble. $Y$ me gustaría que en futuro cercano hubiera autoras consideradas genias al nivel de los autores que ganan los premios de Angoulême. Creo que va a suceder, si no lo evitamos, si intentamos que haya representación de las mujeres en los premios. Es importante. Alguien preguntó una vez: «iPor qué queréis ganar premios?». No se trata de ganar premios: es que si no hay mujeres en las nominaciones se pierde mucha visibilidad, y nunca van a llegar a ser suficientemente reconocidas como para llegar a ser alguien a la altura de un Daniel Clowes, alguien importante en el universo comiquero.

Hablando de premios, a ti, en 2016, te dieron el Premio Gràffica.

Fue una grandísima sorpresa, porque yo no estaba funcionando tanto en la ilustración; mi trabajo estaba teniendo más repercusión a nivel comiquero. Esto me ha hecho dar el salto a un tipo de ilustración editorial diferente, más conceptual y adulta. Me está gustando muchísimo. Pero el premio no me lo esperaba. Me ha lanzado un poco y me ha ayudado bastante.

Al hilo de esto, podemos hablar un poco del proyecto de Tik Tok, ${ }^{4}$ en el que creemos que hay mucho de reivindicación del trabajo de las autoras. Es un proyecto que inicias junto con otras autoras...

No, lo inicié sola, lo que pasa es que a lo largo de los años he tenido colaboradoras

${ }^{4}$ Disponible on line en http://www.tiktokcomics.com/ 


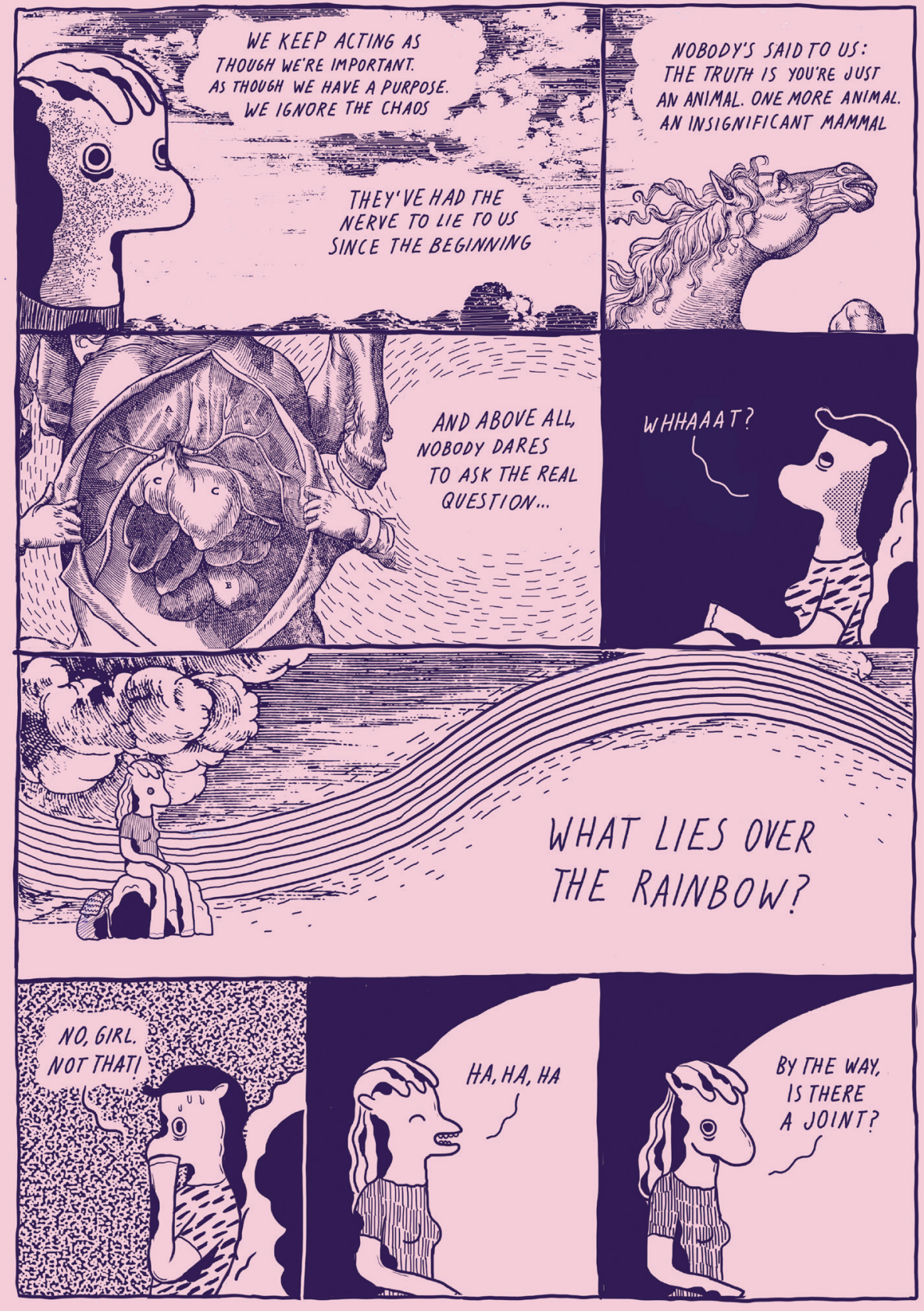

Página de «Horse Meat», historia publicada en Spanish Fever (Fantagraphics, 2016) y originalmente aparecida en España como un fanzine titulado Más allá del arco iris. 
que iban y venían. Pero, al final, como es un trabajo pesado y no remunerado, muchas veces me quedaba yo sola, la corredora de fondo de Tik Tok, que es como estoy ahora. Pero no me importa. Tik Tok en algún momento sí ha tenido esa reivindicación, por ejemplo, con la serie de Teen Wolf, pero realmente no se pretendía que hubiera una paridad forzada. Ha sido algo natural. Las autoras que han llegado ahí es porque estaban en la línea del proyecto y su trabajo era buenísimo. Siempre explico, además, que Tik Tok se ha hecho un poco a sí mismo. Yo no soy tanto una editora que escoge una línea: la han elegido los autores. Yo empecé invitando a ciertas autoras y autores, pero lo fueron dejando... y, de repente, me escribía gente nueva, como Roberto Massó, María Ramos, Begoña García-Alén o Andrés Magán, interesándose por el proyecto. Todos estos autores de una línea más experimental se interesaron por Tik Tok, y se fue formando solo. Realmente, yo no he rechazado a casi nadie, tal vez a alguna persona que estaba demasiado lejos de la línea. Y el hecho de que haya tantas autoras ha sido algo no buscado. Pero es verdad que luego ha habido autoras como Carla Berrocal, Miriampersand o Alixe Lobato, que son tan feministas como yo, con las que creamos la serie Teen Wolf solo con autoras.

Es muy interesante lo que has comentado: cómo empiezas con una generación de autores como pueden ser Marc Torices, la gente de Adobo...

Sí: Alexis Nolla, Joan Cornellá, Pau Anglada... Anglada me parece buenísimo y echo de menos su trabajo, aprovecho para decir1o. También estaban Mirena Ossorno, Miguel B. Núñez... había una mezcla curiosa [risas].
Pero es verdad que luego aparece una nueva generación más experimental, como decías: García-Alén, Andrés Magán, Klari Moreno...

Sí, vino esta nueva ola, de gente super jovencita, haciendo cosas buenísimas. Y se lo han comido todo [risas].

Tik Tok nos parece fundamental, porque fue el primer lugar donde vimos a mucha gente que ahora nos encanta. Es como un manantial de lo nuevo, un lugar donde entrar de vez en cuando a conocer a nuevos autores.

Ahora mismo tengo cierta crisis con Tik Tok. Estoy entre cerrarlo o recuperarlo a tope, no lo sé. No me deja tiempo para hacer mis cosas, pero, por otro lado, me decís esto y me da mucha pena cerrarlo... No lo sé, estoy que no sé qué voy a hacer.

Históricamente, ya ha tenido ese valor para los que nos interesa todo esto.

Yo estoy contentísima con el bien que ha hecho el proyecto. $Y$ no me lo esperaba cuando lo empecé, no sabía que iba a pasar. Que sea un referente para gente joven que ha aprendido a reconocer a esta generación gracias a Tik Tok. Eso está muy bien.

\section{¿Cómo se materializa Teen Wolf en su edi- ción en papel?}

Fue una serie que tuvo éxito y muchas visitas. $\mathrm{Y}$ pensamos en contactar con alguna editorial para que lo publicara. Pensamos, de hecho, en Fulgencio Pimentel, pero antes de poder hablar con nadie, apareció Rubén [Romero] de Fosfatina en un Gutter y nos dijo que lo quería sacar él, que no se lo presentásemos a nadie [risas]. Y yo encantada, 

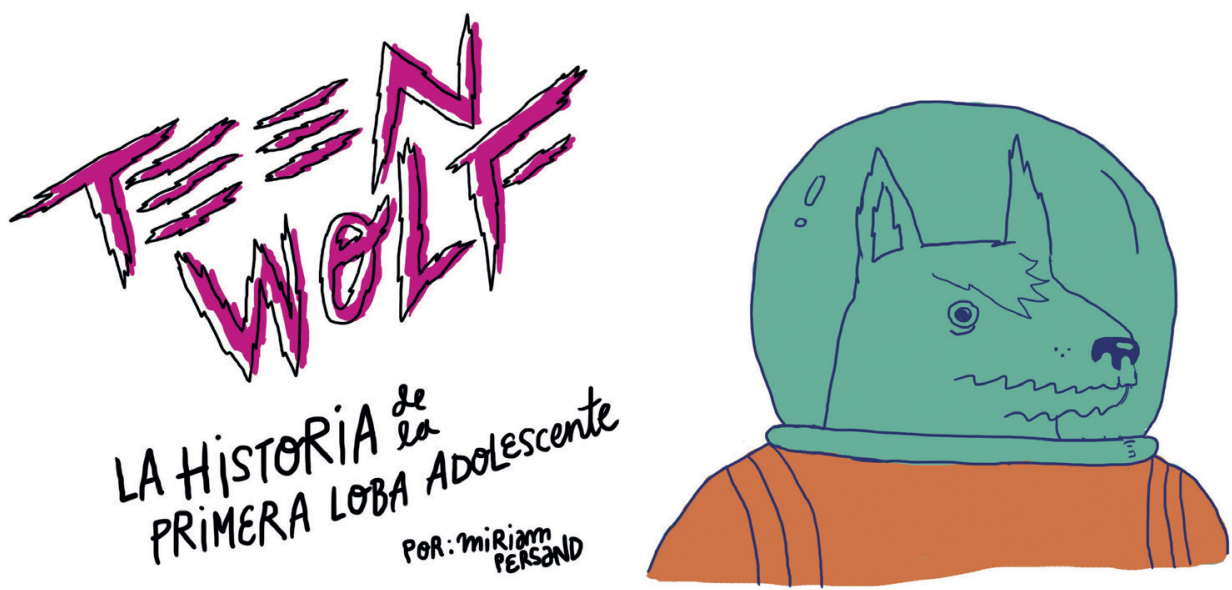

Cabecera de la historia de Miriampersand en Teen Wolf.

claro. En ese momento estaba en Tik Tok Alixe Lobato y nos hicimos amigas de $\mathrm{Ru}-$ bén, y empezamos a urdir el libro de Teen Wolf, en coedición, para que nosotras también trabajásemos en la maquetación y en la coordinación con las autoras.

\section{Tuvo una buena recepción...}

Sí, ha funcionado bien... Hemos hecho muchas presentaciones, una fiesta, ha hecho mucho ruido. En el último GRAF de $\mathrm{Ma}-$ drid [2017] preparé una exposición con las ilustraciones de un pequeño fanzine en risografía que acompañaba a Teen Wolf, que me parecían tan buenas que me daba pena que se quedaran solo ahí. Quedó chulísima. Hay mucho talento en esa antología.

También fue un punto de inflexión para la editorial... Creemos que fue el primer libro en tapa dura que hicieron.

Creo que sí. Después sacaron Hoodoo Voodoo, que fue brutal, con una edición preciosa.

Hay otra cosa interesante. Estamos hablando de la importancia de editoriales como Apa Apa, Fosfatina o DeHavilland -que está últimamente muy inactiva一, pero son todo iniciativas de gente muy apasionada que saca adelante sus proyectos. ¿No crees que puede faltara aún en todo esto la implicación de editoriales un poco más fuertes?

Sí, pero están entrando poco a poco. Lo de DeHavilland es una pena, y espero que vuelvan, porque están dejando un vacío, al ocuparse autores que estaban en otra línea diferente. Pero, por ejemplo, creo que Sapristi empieza a estar interesada en este tipo de cómic, con la publicación del Sadbøi de Berliac (2017). Astiberri creo que ya tiene una línea muy clara y no sé si se va a abrir a otra posibilidad. Y después está La Cúpula, que parece interesada en autores jóvenes. Por ejemplo, acaba de publicar a Anabel Colazo, ${ }^{5}$ que es una fanzinera muy joven pero ya bastante importante. O sea que sí que hay editoriales más grandes que se van interesando.

E incluso una editorial como Apa Apa ha pasado de publicar cómics de grapa a sacar

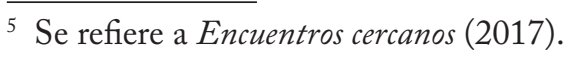


libros contundentes y muy bien editados, como Gran bola de helado de Conxita $\mathrm{He}-$ rrero (2016) o Nuevas estructuras de Begoña García-Alén (2017).

Sí, y de cara a 2018 van a publicar muchas cosas.

\section{Sí, y están intentando vender derechos para la publicación en otros mercados.}

El de Conxita está publicado en Francia, y están intentando publicarlo en EE. UU. Se mueven mucho para sacarnos fuera. Creo que Apa Apa tuvo un punto de inflexión importante, y un cambio en su dinámica distinto, apostando más por autores jóvenes y dándoles visibilidad. Lo están haciendo muy bien. Ahora que todo el mundo lee en inglés, quizá no es tan importante editar ciertos cómics aquí. Puedes comprar las obras de Dash Shaw on line, por ejemplo. Para ellos suponía un gasto tremendo; hablamos de una editorial que no recupera muchísimo económicamente, que lo que hace lo hace por amor al cómic y por creer en todo lo que está pasando ahora.

\section{Con Apa Apa has publicado tu último pro- yecto en cómic, Pulse Enter para continuar.}

El proyecto surge como una propuesta de hacer una historia larga, pero había algo que no funcionaba. Procrastinaba todo lo que podía para no hacerla, había algo que no me gustaba o no me motivaba. Al final hablé con el editor, Toni [Mascaró] y le dije que no quería hacerla, y que prefería empezar de nuevo con otra cosa. Y me propuso hacer un libro con historias cortas, de ocho páginas en adelante, inéditas, y dejar la historia larga para más adelante. Tenía la referencia de Fragmentos seleccionados de Andrés Magán (2017), un cómic de historias cortas que, para mí, funcionó muy bien, y tiene una coherencia. Y trabajé en esa línea de formato.

Gráficamente he querido mantener también cierta coherencia, aunque me cueste, porque siempre estoy cambiando. Hay historias mudas, historias que tienen un hilo argumental muy claro, historias que van saltando adelante y atrás en el tiempo. Pero, por lo menos, quería que estéticamente tuvieran algo que ver.

\section{La edición del libro nos parece sobresa-} liente; ¿cómo ha sido el proceso de producción?

El formato fue idea de Toni Mascaró, que ya tenía experiencia con otros parecidos y funcionaron bien. En mi caso, se añadió un tipo de papel nuevo con más gramaje y una tinta extra plateada en la portada. Sergi Puyol lo maquetó y me dio una idea gráfica para el marco de la segunda historia; esto me gustó tanto, que fue la base de las guardas y algunas páginas intermedias. La idea era que quedara muy vistoso, porque pensábamos que al ser el contenido rarito, había que darle ese extra para hacerlo un poco más atractivo y comercial.

E1 libro consta de cinco historias, alguna de ellas publicada previamente. ¿De dónde viene cada historia, están realizadas en la misma época?

La primera historia había sido publicada previamente en la recopilación Hoodoo Voodoo y pensé que me apetecía mucho incluirla, porque es una de mis historias favoritas, en la que por fin me he atrevido a representar ideas abstractas sobre el espacio y el tiempo. Además, me apetecía mucho realizar una versión en color. La segunda y la tercera historia son versiones largas de 


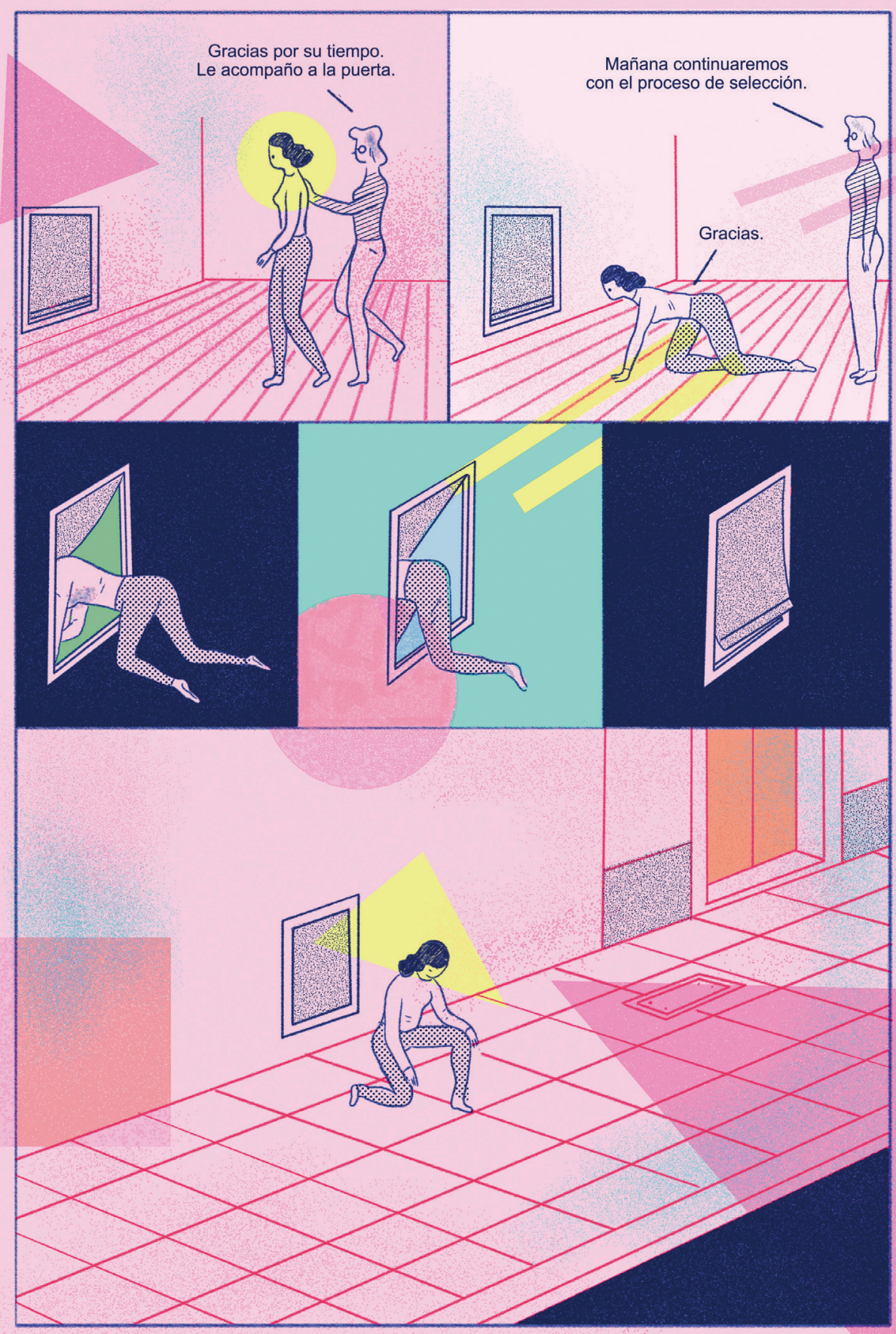

Página de una de las historias incluidas en Pulse Enter para continuar (Apa Apa, 2018). 
otras más cortas que ya tenía. En la tercera en concreto - que trata sobre una entrevista-, quise dar un giro al tipo de humor que tenía en un principio y transformarlo en algo más sutil e inquietante. Por otra parte, le di un aire más de ciencia ficción para que tuviera coherencia con el resto. Las dos últimas historias son totalmente inéditas y realizadas ex profeso para el libro. La última de ellas, «Shinda Kodomo» es la que estaba preparando para que fuera una única historia larga y que al final reconvertí en otra con menos páginas.

\section{En la mayoría de las histo-} rias de Pulse Enter para continuar se aprecia aún tu interés por la ciencia ficción y el terror, pero parece que huyes de las convenciones de estos géneros en el cómic. En cambio, sí que nos ha recordado a cierta ciencia ficción literaria de los años setenta; ¿qué hay de todo esto en el libro?

Puede que sí, porque la mayor parte de ciencia ficción que he leído es de autoras y autores de esa época. Sin embargo, es algo que no he pensado. No hay ninguna intención de homenajear nada en concreto. $\mathrm{Al}$ menos, de forma consciente.

\section{También vemos una crítica social muy ácida, especial- mente en la última historia.}

Me lo han comentado varias veces, pero tampoco he tenido ninguna intención de hacerlo. Me interesaba mucho más hablar del aspecto emocional en esa historia, y de cómo los seres humanos sobrellevamos duramente las pérdidas, sobre todo en las sociedades occidentales en las que todo eso sigue siendo una especie de tabú. El aspecto social de esta historia está creado para sostener esto, ya que necesitaba un contexto y supongo que, de alguna forma, he reproducido una sensación de opresión sistémica. Creo que esto sucede porque yo lo vivo así y sin querer lo he reflejado.

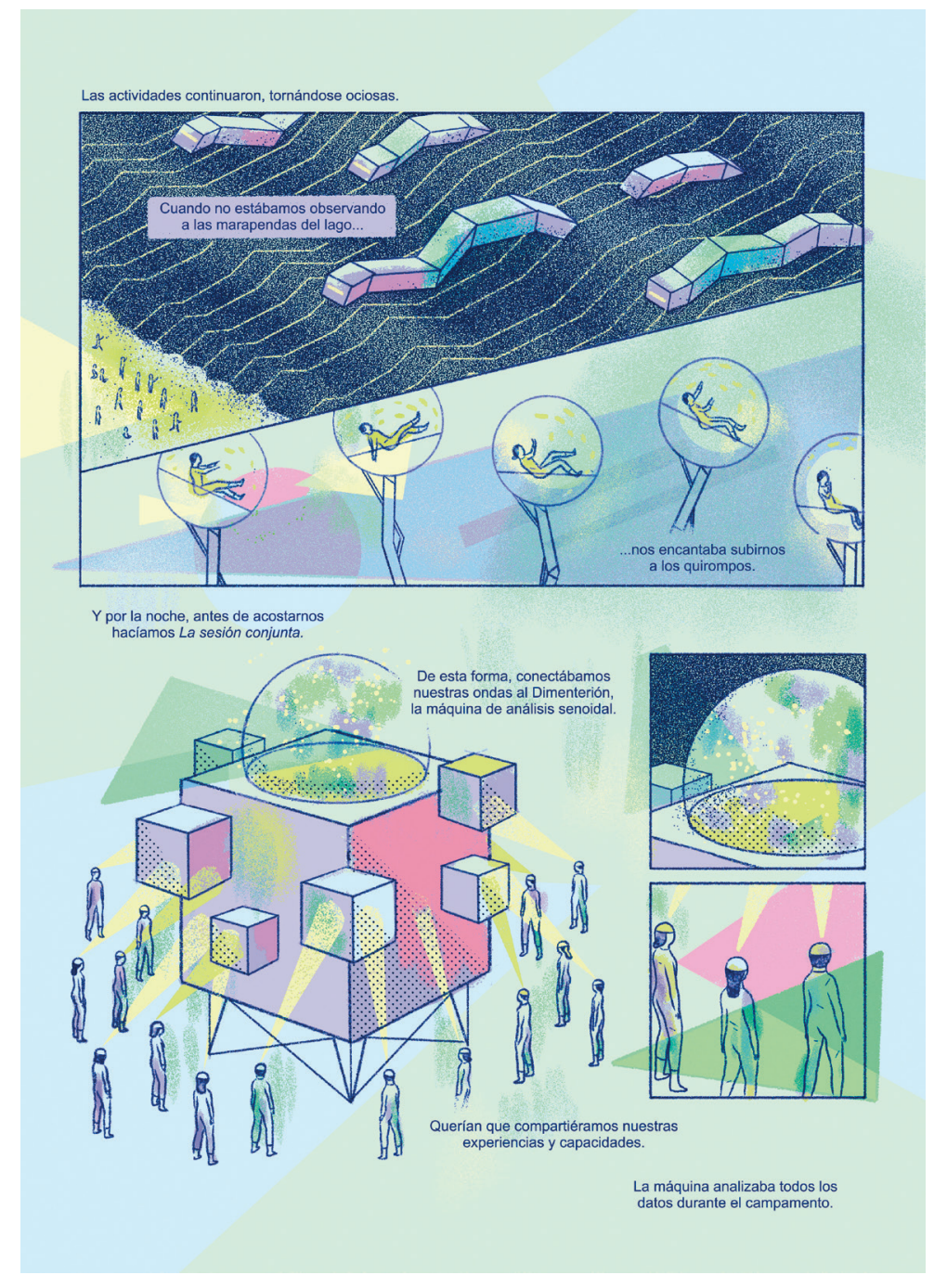

Página de otra historia incluida en Pulse Enter para continuar. 
¿Cómo es tu sistema de trabajo? Antes comentabas que en la historia de Hoodoo Voodoo partiste de una idea, de la intención de representar algo más o menos abstracto. Para las nuevas historias de Pulse Enter para continuar y otras, ¿estás trabajando igual o escribes un guion convencional?

La historia larga que empecé a preparar la he convertido en una más corta, como he comentado antes. Tiene cierta extensión, pero no es una novela gráfica [risas]. Pero siempre parte de una premisa bastante sencilla, y a partir de ahí, desarrollo. Y escribo el guion primero. Sin embargo, a la hora de dibujarlo y estructurar cambio cosas, me voy saliendo del guion. Pero sí necesito que haya un guion previo.

$¿$ Es un guion previo en el que ya planteas cómo va a ser la página y cuántas viñetas va a haber?

No, no. Es un guion escrito, con lo que va a pasar. Algún apunte puede haber sobre el tipo de encuadre o de plano, pero no hay mucho de eso. Eso lo tengo en la cabeza. Me gusta no tenerlo claro, porque así le voy dando vueltas y salen cosas distintas a las ideas que tenía al principio.

\section{Eso te permite variar sobre la marcha.}

Sí. Me acuerdo de una cosa que decía alguien: cuando tú te sales de tu guion y te sorprendes a ti misma, es cuando sorprendes al lector. Y siempre he tenido eso en la cabeza, porque hay muchas historias en las que la gente se espera lo que pasa, es previsible. $\mathrm{Y}$ creo que esto es un recurso para hacerlo menos predecible.

¿Hacer cosas, quizás, menos autoconscientes de los mecanismos de género? «Estoy haciendo una historia de género negro, así que tiene que haber un asesino...» $\mathrm{Ha}^{-}$ cer una cosa más intuitiva.

Totalmente. Menos autoconsciente. Lo suscribo [risas]. 